\title{
ARTICLE \\ Dipeptidyl peptidase 4 inhibitor sitagliptin protected against dextran sulfate sodium-induced experimental colitis by potentiating the action of GLP-2
}

\author{
Meng-meng Ning ${ }^{1}$, Wen-ji Yang ${ }^{1,2}$, Wen-bo Guan ${ }^{1,2}$, Yi-pei Gu ${ }^{1}$, Ying Feng ${ }^{1}$ and Ying Leng ${ }^{1,2}$
}

\begin{abstract}
Dipeptidyl peptidase 4 (DPP4), a ubiquitously expressed protease that cleaves off the N-terminal dipeptide from proline and alanine on the penultimate position, has important roles in many physiological processes. In the present study, experimental colitis was induced in mice receiving 3\% dextran sulfate sodium (DSS) in drinking water. We found that mice with DSS-induced colitis had significantly increased intestinal DPP activity and decreased serum DPP activity, suggesting a probable correlation of DPP4 with experimental colitis. Then, we investigated whether sitagliptin, a specific DPP4 inhibitor could protect against DSS-induced colitis. We showed that oral administration of single dose of sitagliptin $(30 \mathrm{mg} / \mathrm{kg})$ on D7 remarkably inhibited DPP enzyme activity in both serum and intestine of DSS-induced colitic mice. Repeated administration of sitagliptin (10,30 mg/kg, bid, from D0 to D8) significantly ameliorated DSS-induced colitis, including reduction of disease activity index (DAI) and body weight loss, improvement of histological score and colon length. Sitagliptin administration dose-dependently increased plasma concentrations of active form of GLP-1 and colonic expression of GLP-2R. Co-administration of GLP-2R antagonist GLP-2 $2^{3-33}(500 \mu \mathrm{g} / \mathrm{kg}, \mathrm{bid}$, sc) abolished the protective effects of sitagliptin in DSS-induced colitic mice. Moreover, sitagliptin administration significantly decreased the ratio of apoptotic cells and increased the ratio of proliferative cells in colon epithelium of DSS-induced colitic mice, and this effect was also blocked by GLP-2 $2^{3-33}$. Taken together, our results demonstrate that sitagliptin could attenuate DSS-induced experimental colitis and the effects can be attributed to the enhancement of GLP-2 action and the subsequent protective effects on intestinal barrier by inhibiting epithelial cells apoptosis and promoting their proliferation. These findings suggest sitagliptin as a novel therapeutic approach for the treatment of ulcerative colitis.
\end{abstract}

Keywords: ulcerative colitis; dextran sulfate sodium; dipeptidyl peptidase 4; sitagliptin; glucagon-like peptide-2; GLP-2 ${ }^{3-33}$; apoptosis; proliferation

Acta Pharmacologica Sinica (2020) 41:1446-1456; https://doi.org/10.1038/s41401-020-0413-7

\section{INTRODUCTION}

Ulcerative colitis (UC) is a chronic and debilitating inflammatory bowel disease (IBD) characterized by intestinal barrier dysfunction and inflammatory disorder [1]. UC has become a global disease with a high prevalence in Western countries and a rapid increase in incidence in the East, where it previously had a low prevalence $[2,3]$. Limited clinical treatments are currently available, consisting mainly of 5-aminosalicylates, steroids, immunosuppressants, and TNFa antibodies [4]. The insufficient efficacy and severe side effects of existing treatments make it urgent to develop new strategies for the treatment of UC.

Dipeptidyl peptidase 4 (DPP4), also referred to as CD26, as a cell surface antigen on T lymphocytes, is a well-characterized member of the S9b serine protease family. DPP4 is ubiquitously expressed and exists in two forms: a membrane-bound form on the surface of cells, such as lymphocytes and epithelial cells, and a soluble form in extracellular regions, such as blood and other body fluids [5]. DPP4 has various physiological roles either via its enzyme activity by regulating many peptides or via its interactions with various molecules by binding [6]. As a serine protease, it can cleave off the $\mathrm{N}$-terminal dipeptide from proline and alanine at the penultimate position and regulate the metabolism of over 40 bioactive peptides, including chemokines, neuropeptides, and incretin hormones [7]. In addition, it could also interact with many kinds of transmembrane or extracellular matrix proteins, thereby being involved in multiple processes, such as cell adhesion, immune modulation, cell-cell communication and peptide transport $[6,8]$.

Notably, DPP4 cleavage eliminates the biological activity of gut incretin hormones, including glucagon-like peptide-1 (GLP-1) and glucagon-like peptide-2 (GLP-2), which are both glucagon-derived peptides synthesized and released from intestinal endocrine $\mathrm{L}$ cells. GLP-1 is best known for its potential in lowering blood glucose and controlling body weight. Administration of exogenous GLP-1 or its mimetics as well as inhibition of endogenous GLP1 degradation by DPP4 inhibitors were proven to be effective strategies for the treatment of type 2 diabetes. GLP-2, as an intestinotrophic growth factor, was supposed to take part in the

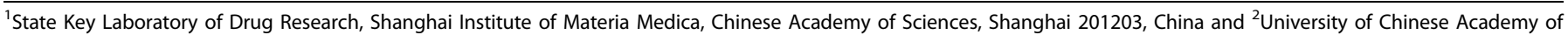
Sciences, Beijing 100049, China

Correspondence: Ying Leng (yleng@simm.ac.cn)
}

Received: 2 January 2020 Accepted: 30 March 2020

Published online: 12 May 2020 
modulation of multiple facets of intestinal physiology, including enhancing crypt cell proliferation, inhibiting epithelial cell apoptosis, and maintaining mucosal integrity [9-12]. Furthermore, exogenous administration of GLP-2 was proven to be effective in alleviating the symptoms of intestinal injuries induced in animal models and in the clinic [13-15]. However, GLP-2 was rapidly degraded by DPP4, resulting in biologically inactive peptides and reducing their potential physiological effects. Thus, inhibiting DPP4 to extend the half-life of GLP-2 may have ameliorative effects on UC.

Although DPP4 exhibits properties correlated with the treatment of UC, the pathophysiological role of DPP4 in UC, the possible beneficial effects of DPP4 inhibitors, and the underlying mechanisms remain ambiguous. Few DPP4 inhibitors have been evaluated in UC mouse models for their curative effects. Some of the inhibitors show certain beneficial effects to some extent, but it is far from sufficient to clarify the above questions since the studies are inadequate and the results are varied [16-20]. The confusion mainly comes from the difference in DPP4 inhibitors employed in the studies, which were developed by separate groups with diverse properties and were not widely acknowledged. Thus, more research is needed to determine the curative potential of DPP4 inhibitors on UC and illuminate the corresponding mechanism(s), which will pave the way for the application of DPP4 inhibitors in the treatment of UC.

Sitagliptin was the first DPP4 inhibitor approved by the FDA for the treatment of type 2 diabetes [21]. Considerable preclinical and clinical data, along with postmarketing surveillance data, proved it to be an efficacious and safe DPP4 inhibitor [22]. In the present study, changes in DPP enzyme activity in the serum and intestine of dextran sulfate sodium (DSS)-induced colitis mice were comprehensively characterized. Then, as a widely accepted drug for the treatment of type 2 diabetes, sitagliptin was employed to explore the probable protective effects against DSS-induced colitis from different aspects, and the underlying mechanism(s) were further investigated.

\section{MATERIALS AND METHODS}

\section{Reagents}

Sitagliptin was obtained from Adamas Reagent Co. (Shanghai, China). DSS with a molecular weight of $36-50 \mathrm{kDa}$ was purchased from MP Biomedicals (Irvine, CA, USA). A fecal occult blood test kit was purchased from Nanjing Jiancheng Bioengineering Institute (Nanjing, China). Gly-Pro-7-AMC was obtained from Sigma-Aldrich (St. Louis, MO, USA). The Alcian blue stain kit was purchased from Solarbio Life Sciences (Beijing, China). The GLP-2 (total) EIA Kit was obtained from Yanaihara Institute (Shizuoka, Japan). GLP-1 (active) ELISA kits and DPP4 inhibitor (DPP-010) were purchased from Merck (Darmstadt, Germany). Synthetic mouse GLP-2 $2^{3-33}$ was provided by GL Biochem (Shanghai, China). TRIzol was obtained from Thermo Fisher Scientific (Waltham, MA, USA). The Prime Script RT Reagent Kit and SYBR Premix Ex Taq Kit were purchased from Takara Biomedical Technology (Dalian, China). A one-step terminal deoxynucleotidyl transferase dUTP nick end labeling (TUNEL) apoptosis assay kit was purchased from Dalian Meilun Biotechnology (Dalian, China). Anti-Ki-67 antibody was purchased from Cell Signaling Technology (Danvers, MA, USA). Alexa Fluor 488 goat anti-mouse $\lg G(H+\mathrm{L})$ was obtained from Thermo Fisher Scientific (Waltham, MA, USA). DAPI (4',6-diamidino-2-phenylindole) was purchased from Beyotime (Shanghai, China).

\section{Animals}

Male BALB/c mice (6-8 weeks) were purchased from Shanghai Lingchang Biotechnology Co. (Shanghai, China). The animals were housed under a 12-h light and 12-h dark cycle and were allowed free access to regular chow and water. Animal experiments were approved by the Institutional Animal Care and Use Committee,
Shanghai Institute of Materia Medica, Chinese Academy of Sciences.

DSS-induced experimental colitis and treatment

Exp 1: To compare DPP enzyme activities in serum and intestinal tissues of normal and DSS-induced colitis mice, mice were randomly divided into 2 groups: normal group and DSS group. Normal group mice were kept with free access to tap water, and DSS group mice were given 3\% DSS in drinking water for 5 days to induce experimental colitis. Mice were killed on day 5. Serum and intestinal tissues (jejunum, ileum, and colon) were snap-frozen and stored at $-80^{\circ} \mathrm{C}$ for DPP enzyme activity assessment.

Exp 2: To examine the inhibitory effect of sitagliptin on DPP enzyme activity in vivo, mice were randomly divided into two groups: normal group and DSS group. Normal mice were kept with free access to tap water, and DSS group mice were given 3\% DSS in drinking water for 7 days to induce experimental colitis. On day 7, normal mice and DSS-induced colitis mice were divided into two groups based on DAI scores: the control group and the sitagliptin group. Sitagliptin $(30 \mathrm{mg} / \mathrm{kg}$ ) or vehicle (distilled water) was orally administered to the corresponding mice. Serum was collected before and at $4 \mathrm{~h}$ and $8 \mathrm{~h}$ after dosing. The intestinal tissues (jejunum, ileum, and colon) were collected at $8 \mathrm{~h}$ after dosing.

Exp 3: To evaluate the therapeutic effect of sitagliptin on DSSinduced colitis, mice were randomly divided into four groups: normal control group, DSS control group, DSS + sitagliptin (10 $\mathrm{mg} / \mathrm{kg}$ ) group and DSS + sitagliptin $(30 \mathrm{mg} / \mathrm{kg})$ group. All animals except the normal control group were given $3 \%$ DSS in drinking water from day 0 to day 7 . Sitagliptin (10 or $30 \mathrm{mg} / \mathrm{kg}$ ) or vehicle (distilled water) was orally administered to mice twice daily from day 0 to day 8 . The disease activity index (DAI) was determined every day. Mice were killed on day 8 , and colons were collected. Blood samples were collected for total GLP-2 and active GLP-1 measurement.

Exp 4: To investigate the involvement of endogenous active GLP-2 in the therapeutic effect of sitagliptin on DSS-induced colitis, the GLP-2 receptor (GLP-2R) antagonist GLP-2 $2^{3-33}$ was utilized. Mice were randomly divided into five groups: normal control group, DSS control group, DSS + sitagliptin $(30 \mathrm{mg} / \mathrm{kg}$ ) group, DSS + GLP-2 $2^{3-33}(500 \mu \mathrm{g} / \mathrm{kg})$ group, and DSS + sitagliptin $(30 \mathrm{mg} / \mathrm{kg})+\mathrm{GLP}-2^{3-33}(500 \mu \mathrm{g} / \mathrm{kg})$ group. Sitagliptin $(30 \mathrm{mg} / \mathrm{kg})$ or vehicle (distilled water) was orally administered to the corresponding mice twice daily. GLP-2 $2^{3-33}(500 \mu \mathrm{g} / \mathrm{kg})$ or vehicle (PBS) was injected subcutaneously into the corresponding mice twice daily. All animals except the normal control group were given $3 \%$ DSS in drinking water from day 0 to day 6 . Sitagliptin and/or GLP-2 ${ }^{3-33}$ were administered from day 0 to day 8 . The DAI was determined every day. Mice were killed on day 8 , and colons were collected.

\section{Evaluation of the DAI}

The DAI was determined as previously described by scoring body weight loss ( 0 points, <1\%; 1 point, $1 \%-5 \%$; 2 points, $5 \%-10 \% ; 3$ points, $10 \%-20 \%$; and 4 points, $>20 \%$ ), stool consistency ( 0 points, well-formed feces; 2 points, semiformed stools; and 4 points, diarrhea) and fecal occult blood (0 points, negative; 2 points, positive; and 4 points, gross bleeding) [23].

\section{DPP enzyme activity examination}

DPP enzyme activities were determined by calculating the cleavage rate of synthetic substrate Gly-Pro-7-AMC. In brief, intestinal tissues $(50 \mathrm{mg} / \mathrm{mL}$ in $50 \mathrm{mM}$ Tris buffer, $\mathrm{pH}$ 7.5) were homogenized at $50 \mathrm{~Hz}$ for $120 \mathrm{~s}$ with a homogenizer. The homogenate was centrifuged at $10,000 \mathrm{rpm}$ for $5 \mathrm{~min}$, and the supernatant was collected. Twenty microliters of supernatant from each sample was added to a 96-well assay plate containing $30 \mu \mathrm{L}$ of buffer. For serum, the method was basically the same. Five 
microliters of serum was added to $45 \mu \mathrm{L}$ of 4-(2-hydroxyethyl)-1piperazineethanesulfonic acid (HEPES) buffer (25 mM HEPES, $140 \mathrm{mM} \mathrm{NaCl}, 80 \mathrm{mM} \mathrm{MgCl}$, pH 7.8). Then, $50 \mu \mathrm{L}$ of Gly-Pro-7AMC $(10 \mu \mathrm{M})$ was added to start the reaction. AMC release was determined by a fluorescence plate reader (excitation at $380 \mathrm{~nm}$ and emission at $460 \mathrm{~nm}$ ). Relative enzyme activity was expressed as the relative fluorescence units produced per second.

Colon collection and measurement

Colons of mice were rapidly removed, and the length was measured. Weight was evaluated after feces were removed. Then, colons were washed with cold saline. The part near the anus was fixed in $4 \%$ neutral paraformaldehyde solution. The rest of the sample was snap-frozen and stored at $-80^{\circ} \mathrm{C}$ for further analysis.

Histological analysis and grades

Colon samples were processed and embedded in paraffin wax. Sections $(4 \mu \mathrm{m})$ were cut and stained with hematoxylin and eosin. Each sample was scored for the following parameters as previously described [24]: inflammatory cell infiltration (0 points, no inflammatory infiltration; 1 point, less inflammatory infiltration in the lamina propria; 2 points, large numbers of inflammatory cells in the lamina propria; 3 points, inflammatory cell infiltration into the submucosa) and tissue lesions (0 points, no damage; 1 point, slight epithelial lesions; 2 points, moderate mucous membrane damage and local ulcers; and 3 points, broad destruction of the mucosal structure and extension to the muscular layer of the intestine).

Alcian blue staining of colon tissue sections was performed using an Alcian Blue Stain Kit according to the manufacturer's instructions. In brief, deparaffinized and hydrated sections were treated with acidizing solution for $3 \mathrm{~min}$ and then stained with Alcian blue for $90 \mathrm{~min}$. Finally, nuclei were counterstained with Nuclear Fixation Red.

Quantitative real-time polymerase chain reaction (qRT-PCR) analysis

Total RNA was extracted from colons using TRIzol. mRNA expression of genes was analyzed using Prime Script RT Reagent Kit with gDNA Eraser and SYBR Premix Ex Taq Kit and detected by Bio-Rad CFX96 Real-Time PCR Detection Systems (Hercules, CA, USA). The primer sequences used here are listed in Table 1. Mouse GAPDH was used as a housekeeping gene.

Measurement of plasma total GLP-2 and active GLP-1

Blood samples of mice were collected $3 \mathrm{~h}$ after the last dosing and placed into tubes containing EDTA- $\mathrm{Na}_{2}$ as an anticoagulant and DPP4 inhibitor (Merck, DPP-010) at a final concentration of $1 \%$. Plasma total GLP-2 levels and active GLP-1 levels were measured using a total GLP-2 EIA kit and GLP-1 (active) ELISA kit according to the manufacturer's instructions.

\section{TUNEL staining}

Paraffin sections of colons were stained with a one-step TUNEL apoptosis assay kit according to its instructions. In brief, colon sections were dewaxed, hydrated, and penetrated by proteinase $\mathrm{K}$ for $30 \mathrm{~min}$ at $37^{\circ} \mathrm{C}$. Then, the TUNEL reaction solution mixed with TdT enzyme and TRITC-dUTP was incubated with samples for 60 min at $37{ }^{\circ} \mathrm{C}$. The nuclei of cells were stained with DAPI. The percentage of TUNEL-positive cells was calculated by dividing the number of positive cells by the total number of cells in crypts. Six crypts per visual field at $\times 200$ magnification and five fields per mouse were studied.

Immunohistochemical staining of Ki-67

Immunostaining for $\mathrm{Ki}-67$ was performed on dewaxed paraformaldehyde-fixed colon sections using anti-Ki-67 primary antibody and a fluorophore-labeled secondary antibody. In brief,
Table 1. Primers used for qRT-PCR analysis.

\begin{tabular}{|c|c|}
\hline Gene & Primers \\
\hline \multirow[t]{2}{*}{ TNF- $\alpha$} & F: 5'-TATGGCCCAGACCCTCACA-3' \\
\hline & R: 5'-GGAGTAGACAAGGTACAACCCATC-3' \\
\hline \multirow[t]{2}{*}{ IL-6 } & F: 5'-CCACTTCACAAGTCGGAGGCTTA-3' \\
\hline & R: 5'-GCAAGTGCATCATCGTTGTTCATAC-3' \\
\hline \multirow[t]{2}{*}{ IL-1 $\beta$} & F: 5'-TCCAGGATGAGGACATGAGCAC-3' \\
\hline & R: 5'-GAACGTCACACACCAGCAGGTTA-3' \\
\hline \multirow[t]{2}{*}{ ZO-1 } & F: 5'-AGGACACCAAAGCATGTGAG-3' \\
\hline & R: 5'-GGCATTCCTGCTGGTTACA-3' \\
\hline \multirow[t]{2}{*}{ Occludin } & F: 5'-TGGCAAGCGATCATACCCAGA-3' \\
\hline & R: 5'-CTGCCTGAAGTCATCCACACTC-3' \\
\hline \multirow[t]{2}{*}{ Claudin } & F: 5'-GGACTGTGGATGTCCTGCGTTT-3' \\
\hline & R: 5'-GCCAATTACCATCAAGGCTCGG-3' \\
\hline \multirow[t]{2}{*}{ Proglucagon } & F: 5'-CTACACCTGTTCGCAGCTCA-3' \\
\hline & R: 5'-CTGGGGTTCTCCTCTGTGTC-3' \\
\hline \multirow[t]{2}{*}{ PC1/3 } & F: 5'-ATGGGCGGCGGAGATC-3' \\
\hline & R: 5'-CCAATCTGACCCAAAAGGTCATAC-3' \\
\hline \multirow[t]{2}{*}{ GLP-2R } & F: 5'-TCTGACAGATATGACATCCATCCAC-3' \\
\hline & R: 5'-TCATCTCCCTCTTCTTGGCTCTTAC-3' \\
\hline \multirow[t]{2}{*}{ DPP4 } & F: 5'-GCATCTGTGGCAAGAGGGGATCAC-3' \\
\hline & R: 5'-GCTGCTCGGATGGACAGTTCC-3' \\
\hline \multirow[t]{2}{*}{ GAPDH } & F: 5'-AGGTCGGTGTGAACGGATTTG-3' \\
\hline & R: 5'-TGTAGACCATGTAGTTGAGGTCA-3' \\
\hline
\end{tabular}

tissue sections were dewaxed, hydrated and blocked with $3 \%$ hydrogen peroxide. Sections were then blocked with $5 \%$ goat serum for $1 \mathrm{~h}$ and incubated with mouse anti-Ki-67 antibody (1:100 diluted) overnight at $4{ }^{\circ} \mathrm{C}$. Alexa Fluor 488 goat anti-mouse IgG (1:100 diluted) was added and incubated for $1 \mathrm{~h}$ at room temperature. Nuclei were stained with DAPI for $2 \mathrm{~min}$. The percentage of Ki-67-positive cells was calculated by dividing the number of positive cells by the total number of cells in crypts. Six crypts per visual field at $\times 200$ magnification and five fields per mouse were studied.

Statistical analysis

Statistical calculations were performed using the GraphPad Prism 5 program (GraphPad Software, San Diego, CA, USA). All data are expressed as the mean \pm SEM. All statistical analyses were performed with a two-tailed unpaired $t$ test. Differences were considered meaningful at $P<0.05$.

\section{RESULTS}

DPP enzyme activity is upregulated in the intestine and downregulated in serum in DSS-induced colitis mice

To address the possible role of DPP4 in the pathogenesis of UC, we examined DPP enzyme activity in normal mice and DSSinduced experimental colitis mice. It has previously been shown that the majority of DPP enzyme activities in serum and intestine are attributable to DPP4, but we cannot exclude the influence of DPP8 and DPP9, which share similar substrates [25-27]. To be precise, we described the activity as DPP enzyme activity here $[19,28]$. Experimental colitis was induced in mice with 3\% DSS in drinking water. On the assay day, the average DAl of colitis mice reached $10.9 \pm 0.2$. The DPP enzyme activities of intestinal tissues were significantly increased in DSS-induced colitis mice, with elevations of $38.7 \%$ in the jejunum, $19.4 \%$ in the ileum, and $41.8 \%$ in the colon (Fig. 1a). However, the serum DPP enzyme activity of colitis mice was significantly decreased by $36.5 \%$ (Fig. 1b). 
a

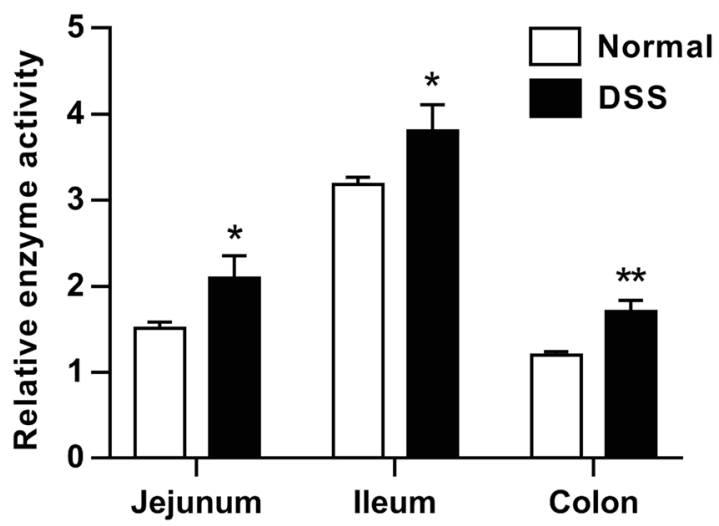

b

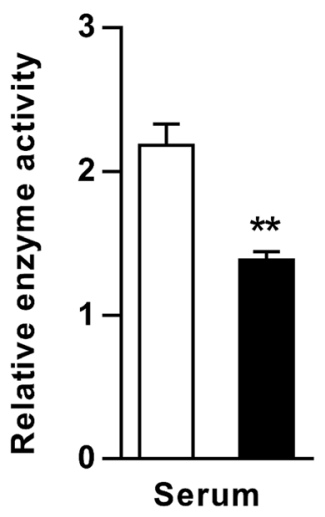

Fig. 1 DPP enzyme activity in serum and intestinal tissues of normal control mice and DSS-induced colitis mice. Mice were treated with $3 \%$ DSS in drinking water for 5 days to induce experimental colitis. a Relative enzyme activity of intestinal tissues $(n=6-10)$. b Relative enzyme activity of serum $(n=10-12)$. Data are expressed as the mean \pm SEM. ${ }^{*} P<0.05,{ }^{* *} P<0.01$ vs the relative normal control.

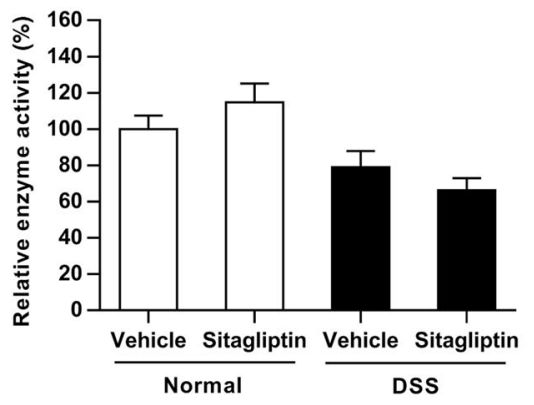

d

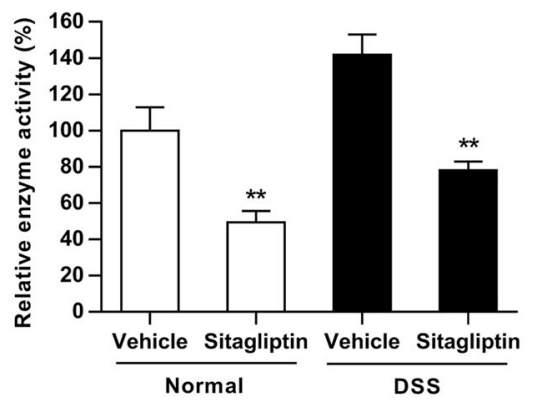

b
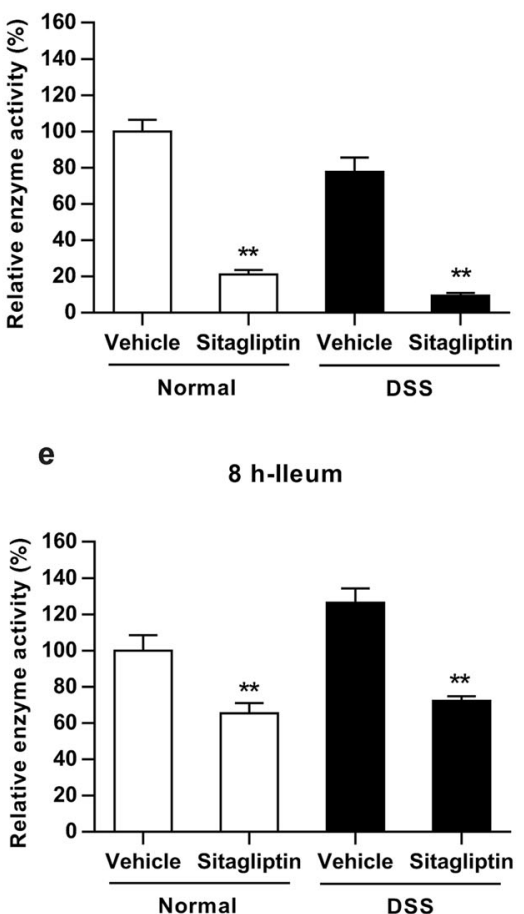

C

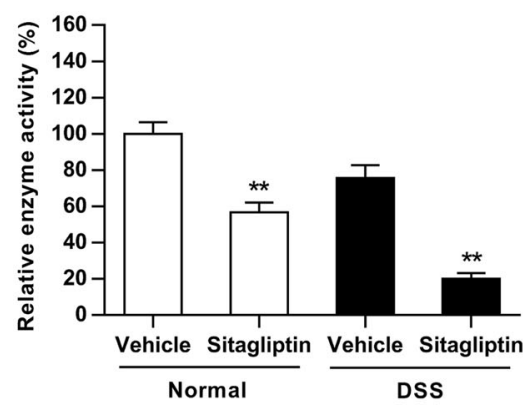

f

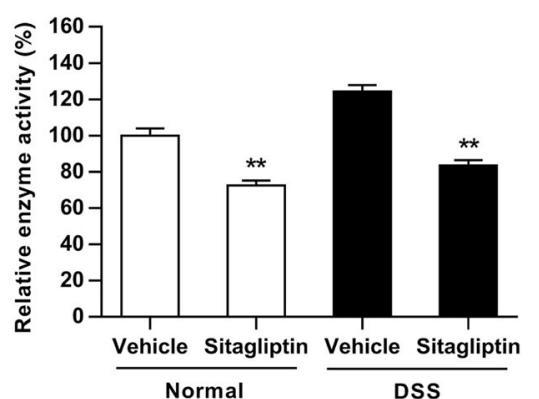

Fig. 2 Inhibitory effects of sitagliptin on DPP enzyme activity in serum and intestine. Mice received $3 \%$ DSS in drinking water for 7 days to induce experimental colitis. A single dose of sitagliptin $(30 \mathrm{mg} / \mathrm{kg})$ or vehicle (distilled water) was orally administered on day 7 . The DPP enzyme activity of serum was determined at different time points after dosing. a $0 \mathrm{~h}, \mathbf{b} 4 \mathrm{~h}, \mathbf{c} 8 \mathrm{~h}$. DPP enzyme activity of different parts of the intestine was determined at $8 \mathrm{~h}$ after dosing. $\mathbf{d}$ Jejunum, e lleum, $\mathbf{f}$ Colon. Data are expressed as the mean \pm SEM $(n=10) .{ }^{* *} P<0.01$ vs the relative vehicle control.

Induction with DSS exerted a negative impact on DPP enzyme activities in serum but a positive impact on DPP enzyme activities in the intestine.

A single oral dose of sitagliptin depressed DPP enzyme activity both in the intestine and serum

Experimental colitis was induced in mice with 3\% DSS in drinking water. On the assay day, the average DAI of colitis mice reached $9.8 \pm 0.3$. Normal mice and DSS-induced experimental colitis mice were orally administered either sitagliptin $(30 \mathrm{mg} / \mathrm{kg}$ ) or vehicle (distilled water). Serum and intestinal segments were collected for the measurement of DPP enzyme activities. As shown in Fig. 2, a single oral dose of $30 \mathrm{mg} / \mathrm{kg}$ sitagliptin significantly inhibited DPP enzyme activities in the intestines and serum in both normal mice and DSS-induced colitis mice. The serum DPP enzyme activity of the sitagliptin group was decreased by $78.8 \%$ and $43.4 \%$ at $4 \mathrm{~h}$ and $8 \mathrm{~h}$ postdose in normal mice and by $87.8 \%$ and $73.5 \%$ in DSSinduced colitis mice. Meanwhile, the DPP enzyme activity was decreased by $50.5 \%, 34.5 \%$, and $27.6 \%$ in the jejunum, ileum, and colon, respectively, at $8 \mathrm{~h}$ post sitagliptin administration in normal 
a

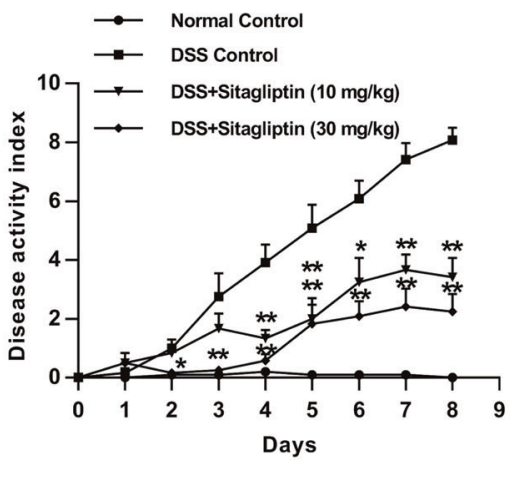

b

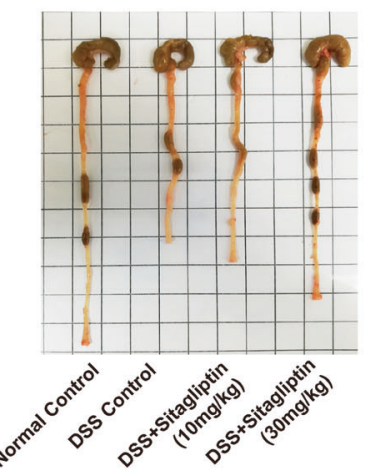

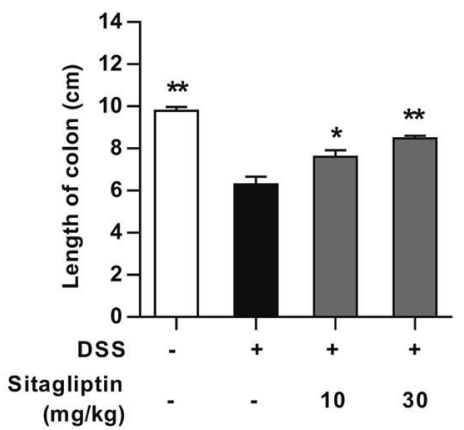

$(\mathrm{mg} / \mathrm{kg})$
30 d

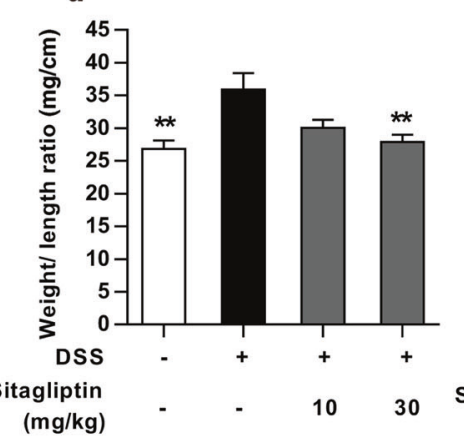

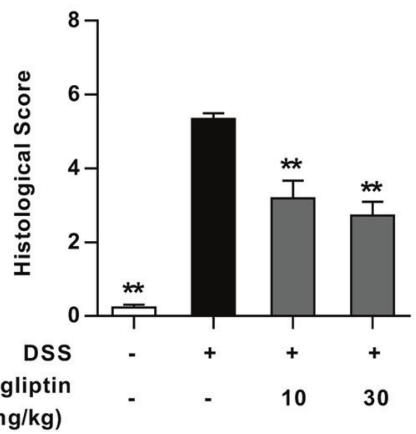

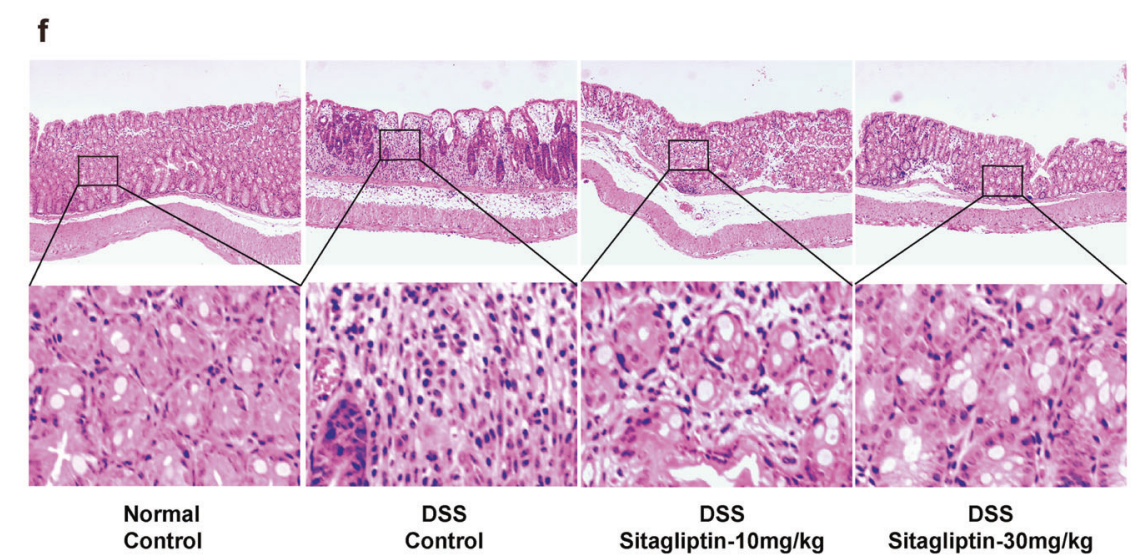

Fig. 3 Sitagliptin improved the symptoms and pathological changes in DSS-induced colitis. DSS (3\%) was given to mice for 7 days to induce experimental colitis in mice. Sitagliptin $(10,30 \mathrm{mg} / \mathrm{kg}$ ) or vehicle (distilled water) was orally administered to the relevant groups from day 0 to day 8 twice daily. a DAl assessment. b Representative images of colons on day 8. c Colon length. d Colon weight/length ratio. e Histological score of colons assigned according to the criteria described in the methods. $\mathbf{f}$ Representative micrographs (magnification $\times 100$ ) and the partially enlarged detail of H\&E-stained sections of colon tissues. Data are expressed as the mean \pm SEM $(n=10-12)$. ${ }^{*} P<0.05,^{* *} P<$ 0.01 vs the DSS control group.

mice. In DSS-induced colitis mice, sitagliptin showed comparable inhibition of DPP enzyme activity with decreased rates of $44.9 \%$, $42.8 \%$, and $32.8 \%$ in the jejunum, ileum, and colon, respectively.

Chronic administration of sitagliptin attenuated DSS-induced experimental colitis

$\mathrm{BALB} / \mathrm{c}$ mice were treated with $3 \% \mathrm{DSS}$ in drinking water from day 0 to day 7. Sitagliptin (10 or $30 \mathrm{mg} / \mathrm{kg}$ ) or vehicle (distilled water) was orally administered to mice twice daily from day 0 to day 8. Sitagliptin administration significantly and dose-dependently decreased the DAl scores from day 4 to day 8 (Fig. 3a). DSS treatment shortened the length of the colon and increased the colon weight/length ratio, whereas sitagliptin administration significantly improved these parameters (Fig. 3b-d). Colonic sections of different groups were histologically stained and examined.
Histological examination showed that DSS induction caused diffuse destruction of the epithelial layer and extensive inflammatory cell infiltration in the epithelium and lamina propria of the colon, and the histological score was markedly increased. Sitagliptin treatment led to less infiltration of inflammatory cells and tissue damage and markedly decreased the histological score (Fig. 3e, f).

Sitagliptin reduced the expression of inflammatory cytokines and increased the expression of tight junction components

Colon tissues of DSS-treated mice exhibited an increase in proinflammatory mediators and partial depletion of tight junction (TJ) components. To investigate the influence of sitagliptin on the expression of inflammation-associated molecules and TJ components, qRT-PCR was performed. As shown in Fig. $4 a-c$, the mRNA levels of TNFa, IL-1 $\beta$, and IL- 6 in the DSS group were significantly 
a
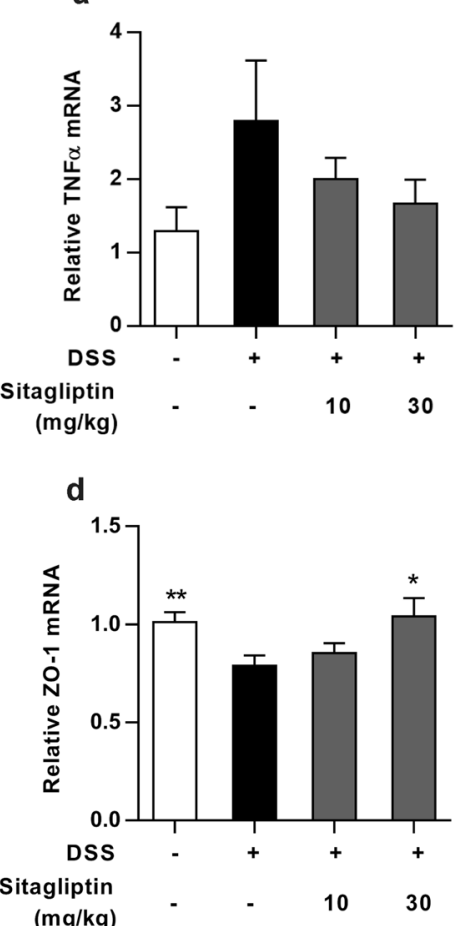

b

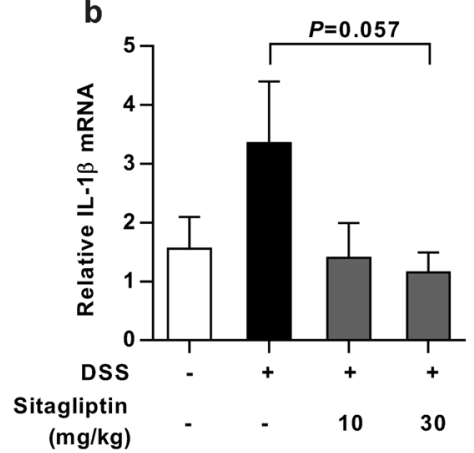

C

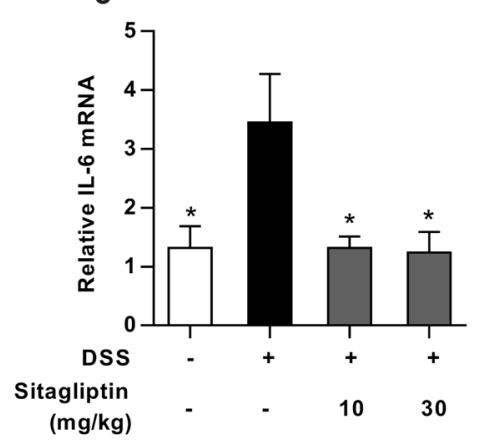

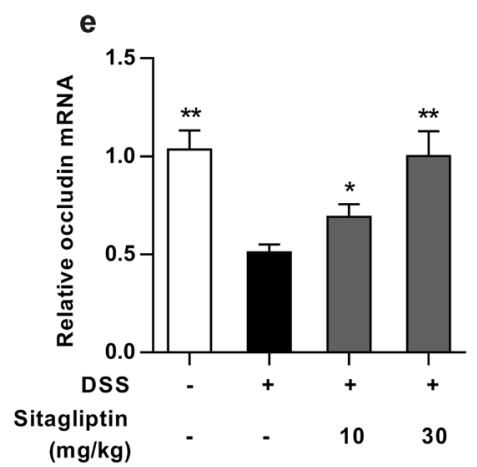

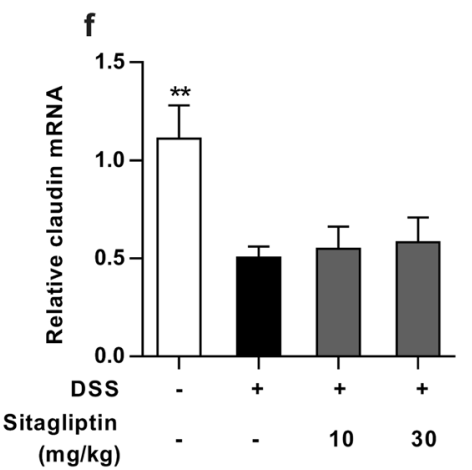

Fig. 4 Effect of sitagliptin on the mRNA expression of proinflammatory mediators and junction-associated components in colons. a TNF $\alpha$, b IL-1 $\beta$, c IL-6, d ZO-1, e occludin, $\mathbf{f}$ claudin. Data are expressed as the mean \pm SEM $(n=10-12) .{ }^{*} P<0.05,{ }^{* *} P<0.01$ vs the DSS control group.

higher or showed an increasing tendency when compared with the normal control group. Sitagliptin administration significantly decreased the mRNA level of IL-6, and a decreasing tendency could also be observed in the mRNA levels of TNFa and IL-1 $\beta$. The barrier function of the gut epithelium was impaired by DSS induction, thus, we examined the influence of sitagliptin on the expression of TJ proteins, which could indicate the barrier function of the intestine. The mRNA levels of ZO-1, claudin and occludin were markedly decreased after DSS treatment, and sitagliptin administration significantly inhibited the reduction in ZO-1 and occludin mRNA expression (Fig. 4d-f).

Sitagliptin increased the expression of GLP-2R and elevated the active form of incretin hormones in plasma

To further characterize the probable association of sitagliptin's protective effects with incretin hormones, especially GLP-2, changes in the levels of incretin hormones and the mRNA levels of related genes were evaluated in normal mice, DSS-induced colitis mice and sitagliptin-treated mice. DSS induction did not cause significant changes in the mRNA levels of proglucagon and prohormone convertase $1 / 3$ (PC1/3), which is responsible for the expression and proteolytic processing of proglucagon to generate GLP-1 and GLP-2 (Fig. 5a, b). An obvious decrease in GLP-2R mRNA levels was observed in DSS-induced colitis mice (Fig. 5c). DPP4 mRNA levels also showed an obvious decrease in DSS-induced colitis mice (Fig. 5d). There was no obvious difference in the plasma concentrations of total GLP-2 and the active form of GLP-1 between normal mice and DSS-induced colitis mice (Fig. 5e, f). Sitagliptin treatment neither affected the gene expression levels of proglucagon and PC1/3 nor affected plasma total GLP-2 concentrations, but it markedly increased the plasma concentrations of the active form of GLP-1 in a dose-dependent manner (Fig. 5f). Sitagliptin increased active form of GLP-1 concentrations, suggesting that it has the potential to elevate the levels of active GLP-2. In addition, as shown in Fig. 5c, sitagliptin increased the expression of GLP-2R, which could further enhance the action of GLP-2.
GLP-2 ${ }^{3-33}$ suppressed the protective effect of sitagliptin on DSSinduced experimental colitis

The truncated fragment GLP-2 $2^{3-33}$ could interact with the GLP-2 receptor as an antagonist of GLP-2R. Here, GLP-2 $2^{3-33}$ was injected subcutaneously into mice alone or in combination with sitagliptin to identify the involvement of endogenously active GLP-2 action in the healing effect of sitagliptin against DSS-induced colitis. As shown in Fig. 6, administration of sitagliptin at a dose of $30 \mathrm{mg} / \mathrm{kg}$ significantly ameliorated the development of DSS-induced colitis, mainly indicated by decreasing DAI scores (Fig. 6a), increasing colon length (Fig. 6b), and decreasing colon weight/length ratio (Fig. 6c). GLP-2 $2^{3-33}$ administration alone did not show any effect, whereas combined treatment with sitagliptin and GLP-2 $2^{3-33}$ partially reversed the healing effect of sitagliptin on DSS-induced colitis. At day 8, the DAl score of the sitagliptin and GLP-2 ${ }^{3-33}$ coadministration group was significantly higher than that of the sitagliptin group, although a moderate improvement could still be observed when compared with the DSS vehicle control group. The increased colon length and decreased colon weight/length ratio caused by sitagliptin treatment were fully blocked by coadministration with GLP-2 ${ }^{3-33}$. Moreover, DSS-treated mice exhibited extensive destruction of the epithelial layer, inflammatory cell infiltration, and a marked reduction in the number of Alcian bluepositive mucous cells, and these histological injuries were significantly relieved by sitagliptin treatment (Fig. $6 d-f$ ). The attenuated histological injuries caused by sitagliptin treatment disappeared in the sitagliptin and GLP-2 $2^{3-33}$ co-administration mice. Therefore, the protective effect of sitagliptin on DSS-induced experimental colitis involved the action of GLP-2.

Sitagliptin decreased apoptosis and increased the proliferation of intestinal epithelial cells in DSS-induced colitis mice by enhancing GLP-2 action

Increased apoptosis and decreased proliferation were reported to have key roles in the pathogenesis of UC [29]. Therefore, we further assessed the effect of sitagliptin on the apoptosis and 


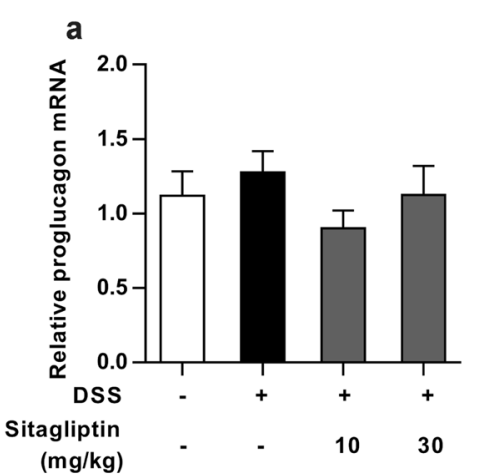

d

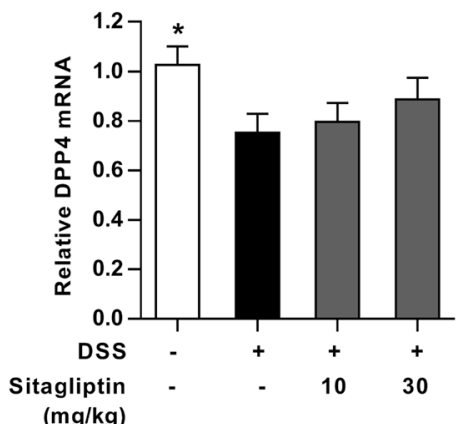

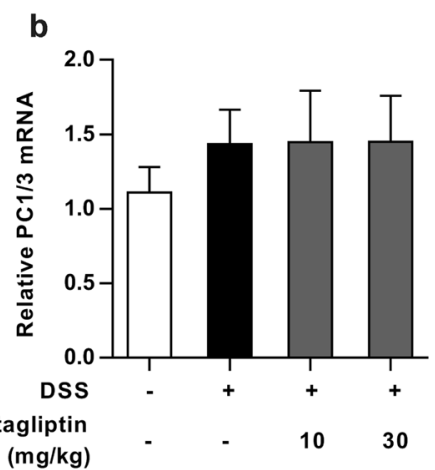

e

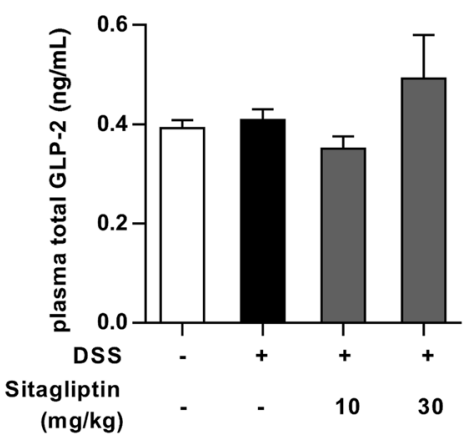

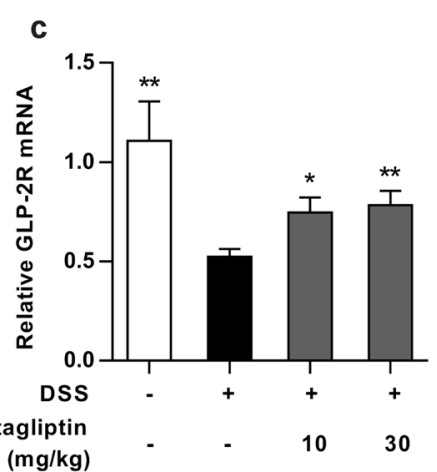

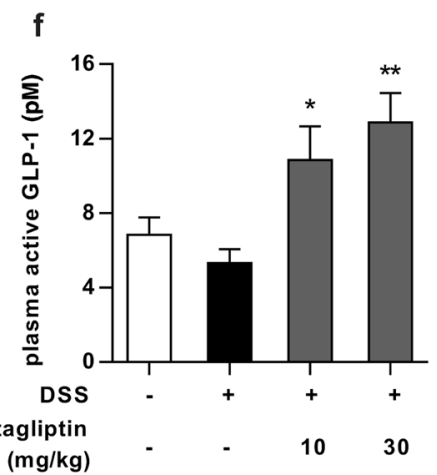

Fig. 5 Influence of sitagliptin on incretin hormones and correlated genes in DSS-induced colitis mice. a Colonic expression of proglucagon mRNA. b Colonic expression of PC1/3 mRNA. c Colonic expression of GLP-2R mRNA. d Colonic expression of DPP4 mRNA. e Levels of plasma total GLP-2. $\mathbf{f}$ Levels of plasma active GLP-1. Data are expressed as the mean \pm SEM $(n=10-12) .{ }^{*} P<0.05,{ }^{* *} P<0.01$ vs the DSS control group.

proliferation of colon epithelial cells. Apoptosis was studied by the TUNEL assay, and cell proliferation was evaluated by Ki-67 immunoreactivity, which indicates the active phases of the cell cycle. The results showed that the number of TUNEL-positive cells in DSS-induced colitis mice was prominent and exhibited a 1.8fold increase compared to that of normal control mice (Fig. 7a, C), but the ratio of Ki-67-positive cells decreased dramatically (Fig. 7b, d). Administration of sitagliptin significantly reduced the ratio of apoptotic cells to colon epithelium and increased the ratio of proliferative cells. GLP-2 $2^{3-33}$ administration alone did not show a significant impact on these two ratios, and co-administration of GLP-2 $2^{3-33}$ with sitagliptin reversed these effects of sitagliptin. Therefore, sitagliptin's protective effects on DSS-induced colitis relied on decreasing the apoptosis and increasing the proliferation of intestinal epithelial cells via the enhancement of GLP-2 action.

\section{DISCUSSION}

DPP4 inhibitors have been widely used as therapeutic drugs for type 2 diabetes owing to their suppression of GLP-1 degradation. GLP-2, which is another incretin hormone derived from proglucagon in enteroendocrine $L$ cells, is also an important substrate of DPP4 and is thought to be associated with tissue repair during intestinal injury. Thus, DPP4 is presumed to be a probable target for the treatment of UC. However, limited research has focused on the correlation of DPP4 with UC, and whether DPP4 inhibitors could become a novel strategy for the treatment of UC and the underlying mechanisms have not been clearly illuminated. In the present study, sitagliptin, a widely used DPP4 inhibitor in the clinical treatment of type 2 diabetes, was proven to be effective in ameliorating the symptoms of DSS-induced experimental colitis. Further research demonstrated that sitagliptin's protective effects involved modulating the proliferation and apoptosis of intestinal epithelial cells via enhancing GLP-2 action.
DPP4, along with DPP8 and DPP9, which are also members of the S9b serine protease family, could cleave off the N-terminal dipeptides containing proline or alanine as their penultimate amino acid. Although DPP4 accounts for the majority of the enzyme activity in serum and intestine, we describe it as DPP enzyme activity here as the available assay cannot exclude the activity of DPP8 and DPP9 completely. Several pathological conditions are associated with altered DPP activity [30]. To disclose the correlation of DPP with UC, it is important to examine whether the DPP enzyme activity has been changed or not under the disease state. Previous research seldom took notice of this issue, so the changes are poorly defined, especially for alterations in the intestine. Mimura and Hildebrandt $[17,31]$ reported that serum DPP enzyme activity was reduced in DSS-induced colitis mice and patients with IBD. Yazbeck observed a decrease in enzyme activity in the membrane fraction of the colon in mice after DSS induction [20]. Another study reported an increase in DPP enzyme activity in the jejunum, but no change was observed in the ileum [25]. No final conclusion has yet been drawn, especially for the changes in the entire intestinal tissues. Herein, we comprehensively assessed the enzyme activity in serum and intestine. Consistent with previous reports and those observed in the serum of patients with UC, we observed a significant decrease in DPP enzyme activity in the serum of experimental colitis mice $[17,31]$. More importantly, an obvious increase in DPP enzyme activity in the intestinal tract was observed in our research. These results suggest the potential importance of DPP4 for the pathophysiology of UC. However, the enzyme activity of DPP was impacted by many factors, such as expression, shedding, and diffusion. The underlying mechanisms for the alteration and the different tendencies in intestinal tissue and serum need further investigation.

The increase in DPP enzyme activity in the intestine after DSS induction observed in our research further emphasized the 


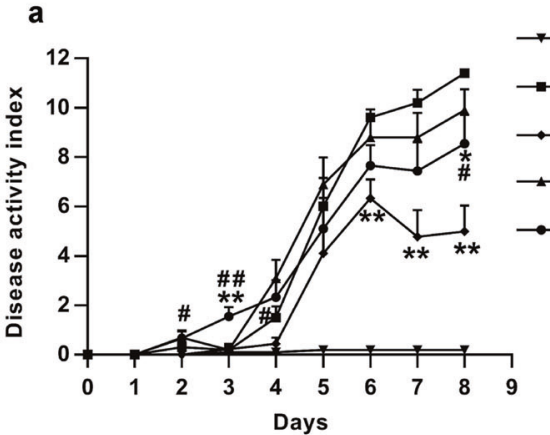

c

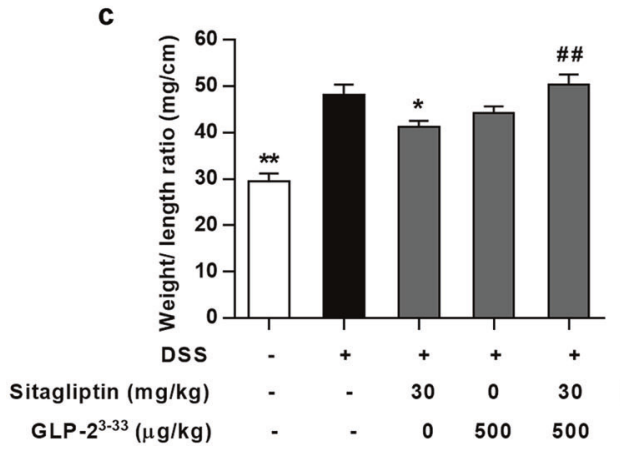

Normal Control

DSS Control

DSS+Sitagliptin (30 mg/kg)

DSS+GLP-2 ${ }^{3.33}(500 \mu \mathrm{g} / \mathrm{kg})$

DSS+Sitagliptin+GLP-2 $2^{3 \cdot 33}$$$
\text { b }
$$

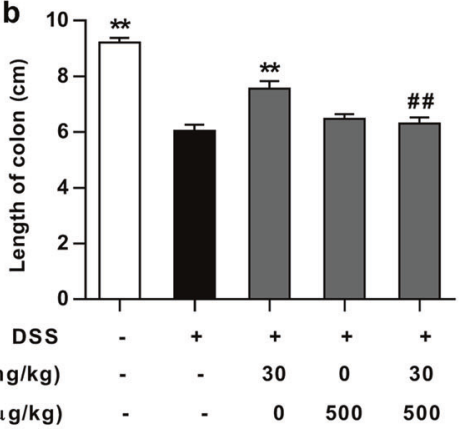

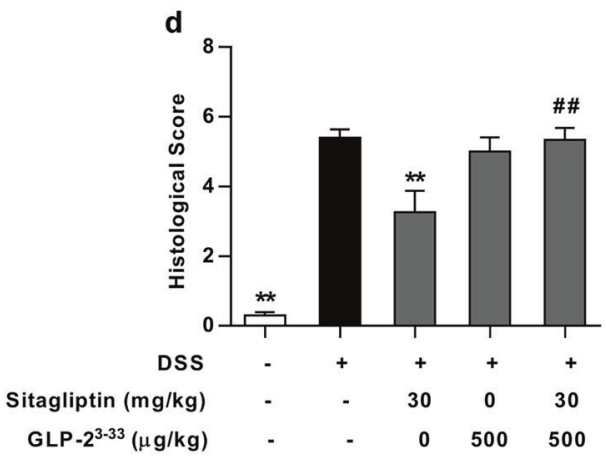

e

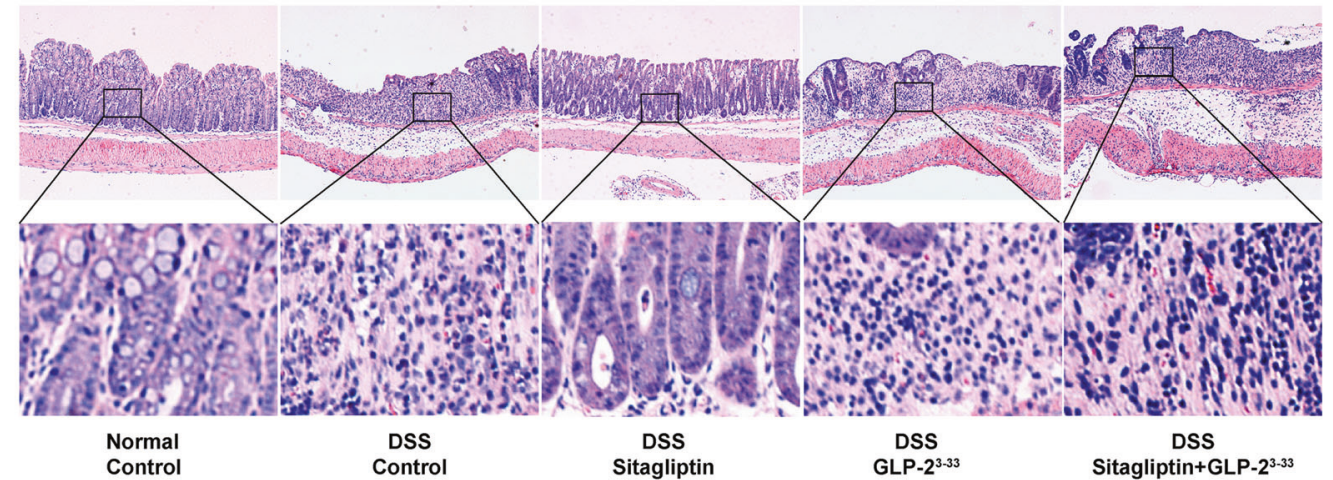

f

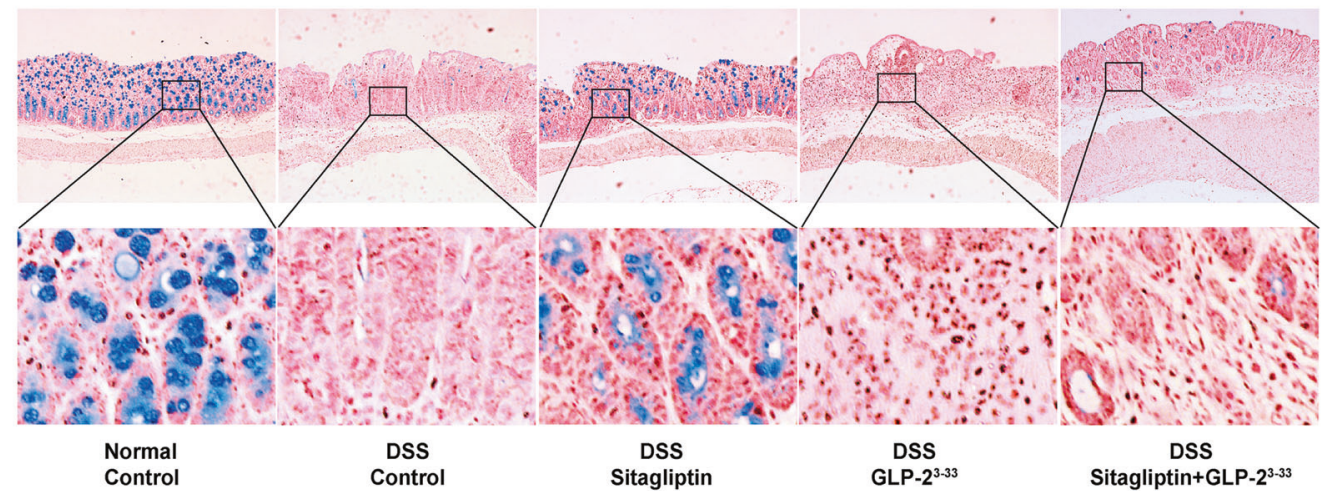

Fig. 6 GLP-2 ${ }^{3-33}$ repressed the protective effect of sitagliptin on the DAI, colon length, colon weight/length ratio, and colon histological injury in DSS-induced colitis mice. DSS (3\%) was given to mice for 6 days to induce experimental colitis in mice. Sitagliptin (30 mg/kg) or vehicle (distilled water) was orally administered to the relevant groups from day 0 to day 8 twice daily. GLP-2 $2^{3-33}$ or vehicle (PBS) was administered subcutaneously to mice from day 0 to day 8 twice daily. a DAl assessment. b Colon length. $\mathbf{c}$ Colon weight/length ratio. d Histological score of colons assigned according to the criteria described in the methods. Representative micrographs (magnification $\times 100$ ) and the partially enlarged detail of different kinds of staining sections of colon tissues. e H\&E. $\mathbf{f}$ Alcian blue. Data are expressed as the mean \pm SEM $(n=9-10)$. ${ }^{*} P<0.05,{ }^{* * *} P<0.01$ vs the DSS control group; ${ }^{\#} P<0.05,{ }^{\# \#} P<0.01$ vs the DSS + sitagliptin (30 mg/kg) group. 
a

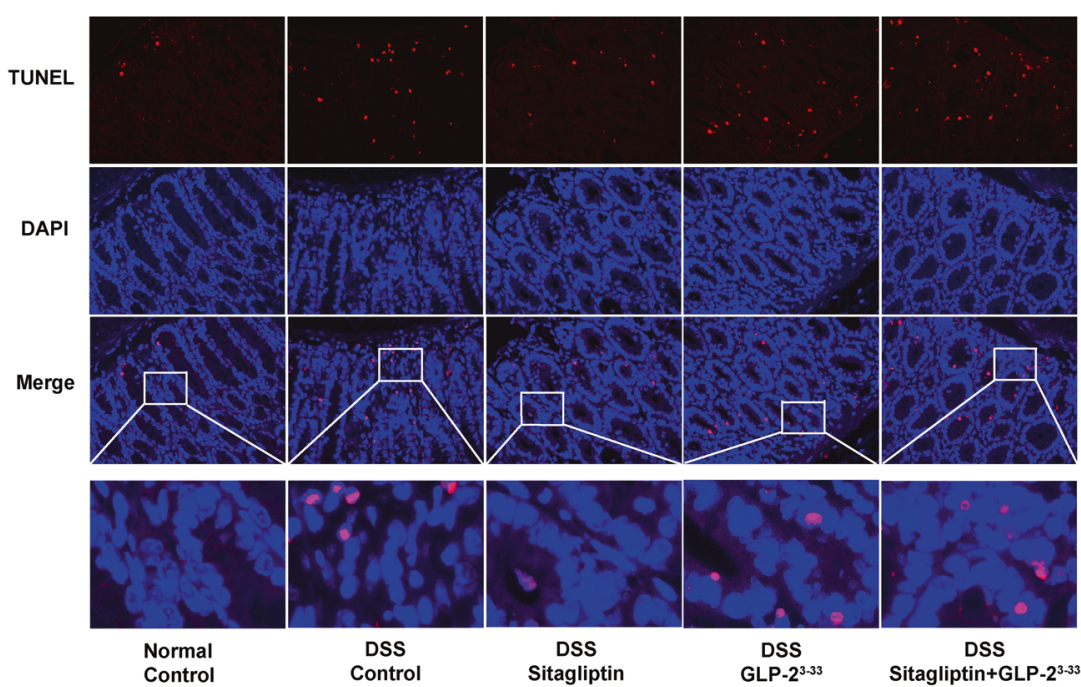

b
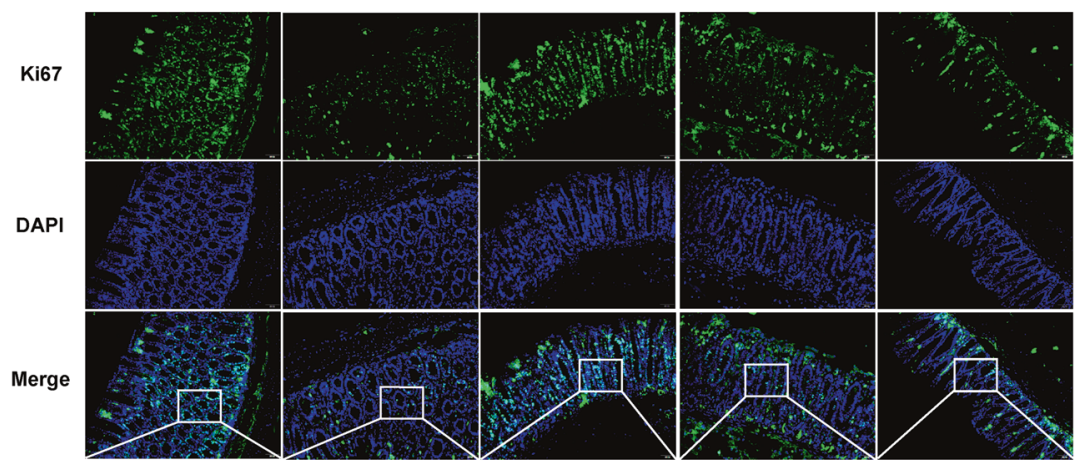

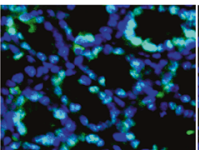

Normal

Control

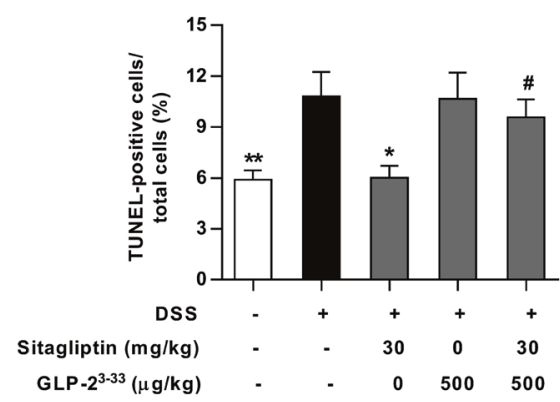

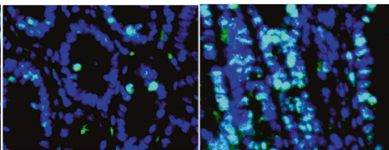

DSS Sitagliptin

d

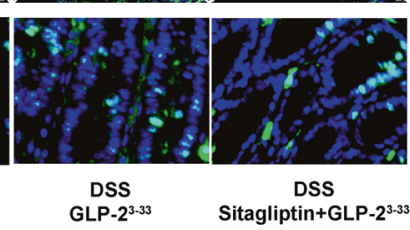

Sitagliptin+GLP-2 ${ }^{3-3}$

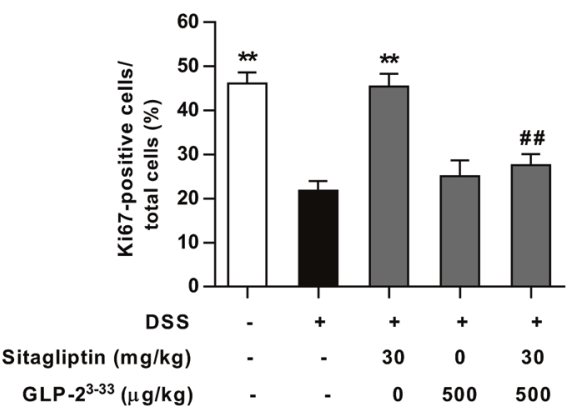

Fig. 7 The modulatory effects of sitagliptin on the apoptosis and proliferation of colonic epithelial cells were repressed by GLP-2 ${ }^{3-33}$ in DSS-induced colitis mice. a Representative micrographs (magnification $\times 400$ ) and the partially enlarged detail of TUNEL-stained sections. b Representative micrographs (magnification $\times 200$ ) and the partially enlarged detail of Ki-67 immunostained sections. c Quantification of TUNEL-positive cells in each group. $\mathbf{d}$ Quantitative analysis of Ki-67-positive cells in each group. Data are expressed as the mean \pm SEM $(n=$ 9-10). ${ }^{*} P<0.05,{ }^{* *} P<0.01$ vs the DSS control group; ${ }^{\#} P<0.05$, ${ }^{\# \# ~} P<0.01$ vs the DSS + sitagliptin (30 mg/kg) group.

importance of DPP4 in the intestine. As a specific DPP4 inhibitor, sitagliptin could significantly inhibit DPP enzyme activities in plasma or serum in different animal models or humans [32-34]. However, the inhibition efficacy of sitagliptin on intestinal DPP enzyme activity in experimental colitis models has not previously been determined. Thus, we evaluated the inhibitory effect of sitagliptin on DPP enzyme activity in both serum and intestinal tissues in normal mice and DSS-induced experimental colitis mice. As expected, single oral administration of sitagliptin significantly suppressed DPP activity in serum. Furthermore, it exhibited robust inhibitory effects in the intestine both in normal mice and DSSinduced colitis mice. These results suggested a potential role of 
sitagliptin in elevating active incretin hormone levels not only in normal mice but also in DSS-induced colitis mice.

Next, the therapeutic effects of sitagliptin against DSS-induced colitis were examined. Sitagliptin $(30 \mathrm{mg} / \mathrm{kg})$ exhibited a significant improving effect on the DAI score as early as day 2 and lasted until the final day. The colon length, weight/length ratio, and morphological analysis provided additional evidence of sitagliptin's effectiveness. To date, only a few DPP4 inhibitors have been tested in UC mouse models [16-20]. Among them, anagliptin and ER-319711 are two specific DPP4 inhibitors that were reported to show anticolitis effects in animal models. These results seem to be encouraging and shed light on the application of DPP4 inhibitors in the treatment of UC. However, there is still much doubt about the conclusion, as the improvement effects exhibited by DPP4 inhibitors are distinct and ambiguous. For example, anagliptin, which has already been used in the clinic for the treatment of type 2 diabetes, improved body weight loss and the DAI in the recovery phase of DSS-induced colitis but did not exhibit obvious amelioration during the entire DSS induction period [17]. In line with anagliptin, ER-319711 showed minimal ameliorative effects on DSS-induced experimental colitis and even caused a decrease in body weight in the early days of treatment [16]. In comparison, sitagliptin exhibited an impressive protective effect in DSSinduced colitis. We suspected that the discrepancy comes from their different properties, especially their distribution in the intestine and their different inhibitory efficacies.

DPP4 inhibitors were supposed to have ameliorative effects on UC by inhibiting GLP-2 degradation. The prerequisite for this hypothesis is to ensure that GLP-2-related functions are intact in patients with UC. Herein, we measured the expression of genes related to GLP-2 generation, degradation and signal transduction. GLP-2 is encoded by the proglucagon gene, which is expressed as a single mRNA and is translated to a precursor protein. Posttranslational proteolytic processing, which is mainly mediated by PC1/3 in the intestine, generates GLP-2 [35]. GLP-2 binds to the GLP-2 receptor and produces effects. Our results showed that the expression of proglucagon and PC $1 / 3$ was not visibly changed in colitis mice compared with normal control mice. Meanwhile, the DPP4 mRNA expression level was decreased in DSS-induced colitis mice, which indicated that the increase in DPP enzyme activity we observed in the colon could not be simply attributed to the changes in DPP4 mRNA expression. Further detailed studies are needed to address the possible mechanisms underlying the elevation of DPP enzyme activity in the colon of DSS-induced colitis mice. Moreover, the plasma levels of total GLP-2 and the active form of GLP-1 in colitis mice were also equivalent to those of normal mice. These results indicated that the GLP-2 producing capacity is conserved in the setting of experimental colitis. It is worth noting that the expression level of GLP-2R decreased markedly in colitis mice, which might impair the signal transduction of GLP-2. As expected, sitagliptin did not affect the mRNA expression of proglucagon and $\mathrm{PC} 1 / 3$ or the plasma levels of total GLP-2. However, sitagliptin was capable of increasing the levels of the active form of incretin hormones, as indicated by the elevation of the active form of GLP-1 in the plasma. It is unfortunate that there is no active GLP-2 assay kit available commercially, so we were unable to examine the concentration of active GLP-2 directly. However, it is also noteworthy that sitagliptin treatment restored the decrease in GLP-2R expression induced by DSS. It seems to be a particular capacity of sitagliptin, as EMDB-1, which is a peptide inhibitor of DPP4, was reported to reduce the expression of GLP$2 \mathrm{R}$ both in normal mice and TNBS-induced CD mouse models [19]. Interestingly, a decrease in GLP-2R protein expression in the colon was also observed in patients with UC, which was in accordance with our observation in DSS-induced colitis mice [19]. Taken together, our results suggest that the GLP-2-generating potential remained intact in DSS-induced colitis mouse models. Sitagliptin was able to enhance GLP-2 action not only by elevating the active
GLP-2 concentration but also by increasing GLP-2R expression, thus reinforcing its signal transduction.

To clarify whether endogenous active GLP-2 is involved in the therapeutic effects of sitagliptin, GLP-2 $2^{3-33}$, as an antagonist of GLP-2R, was employed to evaluate whether it could block the protective effect of sitagliptin. Our results demonstrated that coadministration of GLP-2 $2^{3-33}$ repressed the ameliorating effect of sitagliptin on experimental colitis. The results indicated that sitagliptin exerted its effect at least partially via potentiating GLP2 action. Meanwhile, increased apoptosis and decreased proliferation were suggested to be the key elements leading to the collapse of the intestinal epithelial barrier and subsequently facilitating the invasion of luminal microorganisms and triggering a battery of symptoms [29]. However, whether DPP4 exerts its effect by modulating the proliferation and apoptosis of colonic epithelial cells via GLP-2 has not been defined until now. Our results showed that the balance of apoptosis and proliferation was disrupted in the epithelium of colon in DSS-induced colitis mice, with a significant increase in apoptosis and an obvious decrease in proliferation, in line with previous research [29]. Sitagliptin treatment increased the proliferation of colonic epithelial cells in DSS-induced colitis mice. More importantly, it decreased apoptosis, which was supposed to be an early event during the onset of UC and is mainly responsible for the loss of colonic epithelium in patients with active UC. Taken together, sitagliptin could improve the homeostasis of apoptosis and proliferation of intestinal epithelial cells damaged by DSS, and these capacities could be attributed to the enhancement in GLP2 action, as application of GLP-2 $2^{3-33}$ abolished these favorable effects.

\section{CONCLUSION}

In conclusion, our work revealed a decrease in DPP enzyme activity in serum and an increase in intestinal tissues of DSSinduced colitis mice, indicating a possible correlation of DPP4 with UC. Sitagliptin showed a remarkable protective effect against DSSinduced colitis, which involved the enhancement of endogenous GLP-2 action and subsequent inhibition of apoptosis and promotion of proliferation in the intestinal epithelial barrier. Our results provide further preclinical evidence for the potential therapeutic use of DPP4 inhibitors in the treatment of UC.

\section{ACKNOWLEDGEMENTS}

This study was financially supported by a grant from the National Natural Science Foundation of China (no. 81872922).

\section{AUTHOR CONTRIBUTIONS}

MMN and YL designed the study. MMN, WJY, WBG, YPG, and YF conducted the experiments. MMN and WBG analyzed the data. MMN and $Y L$ wrote the manuscript.

\section{ADDITIONAL INFORMATION}

Competing interests: The authors declare no competing interests.

\section{REFERENCES}

1. Loddo I, Romano C. Inflammatory bowel disease: genetics, epigenetics, and pathogenesis. Front Immunol. 2015;6:551.

2. Ng SC, Shi HY, Hamidi N, Underwood FE, Tang W, Benchimol El, et al. Worldwide incidence and prevalence of inflammatory bowel disease in the 21st century: a systematic review of population-based studies. Lancet. 2018;390:2769-78.

3. Mak WY, Zhao M, Ng SC, Burisch J. The epidemiology of inflammatory bowel disease: east meets west. J Gastroenterol Hepatol. 2020;35:380-9.

4. Lucafò M, Franca R, Selvestrel D, Curci D, Pugnetti L, Decorti G, et al. Pharmacogenetics of treatments for inflammatory bowel disease. Expert Opin Drug Metab Toxicol. 2018;14:1209-23. 
5. Matteucci E, Giampietro O. Dipeptidyl peptidase-4 (CD26): knowing the function before inhibiting the enzyme. Curr Med Chem. 2009;16:2943-51.

6. Klemann C, Wagner L, Stephan M, von Hörsten S. Cut to the chase: a review of CD26/dipeptidyl peptidase-4's (DPP4) entanglement in the immune system. Clin Exp Immunol. 2016;185:1-21.

7. Mulvihill EE, Drucker DJ. Pharmacology, physiology, and mechanisms of action of dipeptidyl peptidase-4 inhibitors. Endocr Rev. 2014;35:992-1019.

8. Birnbaum Y, Bajaj M, Qian J, Ye Y. Dipeptidyl peptidase-4 inhibition by Saxagliptin prevents inflammation and renal injury by targeting the Nlrp3/ASC inflammasome. BMJ Open Diabetes Res Care. 2016;4:e000227.

9. Benjamin MA, McKay DM, Yang PC, Cameron H, Perdue MH. Glucagon-like peptide-2 enhances intestinal epithelial barrier function of both transcellular and paracellular pathways in the mouse. Gut. 2000;47:112-9.

10. Bremholm L, Hornum M, Henriksen BM, Larsen S, Holst JJ. Glucagon-like peptide-2 increases mesenteric blood flow in humans. Scand J Gastroenterol. 2009;44:314-9.

11. Janssen $P$, Rotondo A, Mulé F, Tack J. Review article: a comparison of glucagonlike peptides 1 and 2. Aliment Pharmacol Ther. 2013;37:18-36.

12. Kato $Y, Y u D$, Schwartz MZ. Glucagonlike peptide-2 enhances small intestinal absorptive function and mucosal mass in vivo. J Pediatr Surg. 1999;34:18-20.

13. Boushey RP, Yusta B, Drucker DJ. Glucagon-like peptide 2 decreases mortality and reduces the severity of indomethacin-induced murine enteritis. Am J Physiol. 1999;277:E937-47.

14. Boushey RP, Yusta B, Drucker DJ. Glucagon-like peptide (GLP)-2 reduces chemotherapy-associated mortality and enhances cell survival in cells expressing a transfected GLP-2 receptor. Cancer Res. 2001;61:687-93.

15. Nakame K, Kaji T, Mukai M, Shinyama S, Matsufuji H. The protective and antiinflammatory effects of glucagon-like peptide-2 in an experimental rat model of necrotizing enterocolitis. Peptides. 2016;75:1-7.

16. Ban H, Bamba S, Imaeda H, Inatomi O, Kobori A, Sasaki M, et al. The DPP-IV inhibitor ER-319711 has a proliferative effect on the colonic epithelium and a minimal effect in the amelioration of colitis. Oncol Rep. 2011;25:1699-703.

17. Mimura S, Ando T, Ishiguro K, Maeda O, Watanabe O, Ujihara M, et al. Dipeptidyl peptidase-4 inhibitor anagliptin facilitates restoration of dextran sulfate sodiuminduced colitis. Scand J Gastroenterol. 2013;48:1152-9.

18. Salaga M, Binienda A, Draczkowski $P$, Kosson $P$, Kordek $R$, Jozwiak K, et al. Novel peptide inhibitor of dipeptidyl peptidase IV (Tyr-Pro-D-Ala- $\mathrm{NH}_{2}$ ) with antiinflammatory activity in the mouse models of colitis. Peptides. 2018;108:34-45.

19. Salaga M, Mokrowiecka A, Zielinska M, Malecka-Panas E, Kordek R, Kamysz E, et al. New peptide inhibitor of dipeptidyl peptidase IV, EMDB-1 extends the half-life of GLP-2 and attenuates colitis in mice after topical administration. J Pharmacol Exp Ther. 2017;363:92-103

20. Yazbeck R, Sulda ML, Howarth GS, Bleich A, Raber $K$, von Hörsten $S$, et al. Dipeptidyl peptidase expression during experimental colitis in mice. Inflamm Bowel Dis. 2010;16:1340-51.
21. Lee M, Rhee MK. Sitagliptin for Type 2 diabetes: a 2015 update. Expert Rev Cardiovasc Ther. 2015;13:597-610.

22. Ceriello A, Sportiello L, Rafaniello C, Rossi F. DPP-4 inhibitors: pharmacological differences and their clinical implications. Expert Opin Drug Saf. 2014; 13(Suppl 1):S57-68.

23. Zou Y, Lin J, Li W, Wu Z, He Z, Huang G, et al. Huangqin-tang ameliorates dextran sodium sulphate-induced colitis by regulating intestinal epithelial cell homeostasis, inflammation and immune response. Sci Rep. 2016;6:39299.

24. Matsunaga T, Hashimoto S, Yamamoto N, Kawasato R, Shirasawa T, Goto A, et al. Protective effect of daikenchuto on dextran sulfate sodium-induced colitis in mice. Gastroenterol Res Pract. 2017;2017:1298263.

25. Yazbeck R, Howarth GS, Butler RN, Geier MS, Abbott CA. Biochemical and histological changes in the small intestine of mice with dextran sulfate sodium colitis. J Cell Physiol. 2011;226:3219-24.

26. Durinx C, Lambeir AM, Bosmans E, Falmagne JB, Berghmans $R$, Haemers $A$, et al. Molecular characterization of dipeptidyl peptidase activity in serum: soluble CD26/dipeptidyl peptidase IV is responsible for the release of X-Pro dipeptides. Eur J Biochem. 2000;267:5608-13.

27. Friedrich D, Hoffmann T, Bär J, Wermann M, Manhart S, Heiser U, et al. Does human attractin have DP4 activity? Biol Chem. 2007;388:155-62.

28. Zhang $H$, Chen $Y$, Keane FM, Gorrell MD. Advances in understanding the expression and function of dipeptidyl peptidase 8 and 9. Mol Cancer Res. 2013;11:1487-96.

29. Araki Y, Mukaisyo K, Sugihara H, Fujiyama Y, Hattori T. Increased apoptosis and decreased proliferation of colonic epithelium in dextran sulfate sodium-induced colitis in mice. Oncol Rep. 2010;24:869-74.

30. Korom S, De Meester I, Stadlbauer TH, Chandraker A, Schaub M, Sayegh MH, et al. Inhibition of CD26/dipeptidyl peptidase IV activity in vivo prolongs cardiac allograft survival in rat recipients. Transplantation. 1997;63:1495-500.

31. Hildebrandt M, Rose M, Ruter J, Salama A, Mönnikes H, Klapp BF. Dipeptidyl peptidase IV (DP IV, CD26) in patients with inflammatory bowel disease. Scand J Gastroenterol. 2001;36:1067-72.

32. Lee TM, Chen WT, Chang NC. Dipeptidyl peptidase-4 inhibition attenuates arrhythmias via a protein kinase A-dependent pathway in infarcted hearts. Circ J. 2015;79:2461-70.

33. Mulvihill EE, Varin EM, Gladanac B, Campbell JE, Ussher JR, Baggio LL, et al. Cellular sites and mechanisms linking reduction of dipeptidyl peptidase-4 activity to control of incretin hormone action and glucose homeostasis. Cell Metab. 2017;25:152-65.

34. Reichetzeder C, von Websky K, Tsuprykov O, Mohagheghi Samarin A, Falke LG, Dwi Putra SE, et al. Head-to-head comparison of structurally unrelated dipeptidyl peptidase 4 inhibitors in the setting of renal ischemia reperfusion injury. $\mathrm{Br} \mathrm{J}$ Pharmacol. 2017;174:2273-86.

35. Kieffer TJ, Habener JF. The glucagon-like peptides. Endocr Rev. 1999;20:876-913. 